INTERNATIONAL JOURNAL OF CURRENT RESEARCH IN CHEMISTRY AND PHARMACEUTICAL SCIENCES

(p-ISSN: 2348-5213: e-ISSN: 2348-5221)

wWw.ijcrcps.com

DOI: $10.22192 /$ ijcrcps

Coden: IJCROO(USA)

Volume 7, Issue 4 - 2020

Research Article

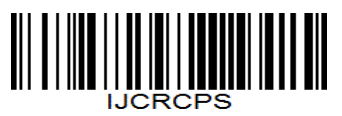

DOI: http://dx.doi.org/10.22192/ijcrcps.2020.07.04.004

\title{
Effect of Ripening Time of Fruits in the Chemical Composition (\%) of Essential Oils in Syrian Laurel Oil
}

\author{
Abdul Aziz Ramadan ${ }^{1 *}$, Hasna Mandil ${ }^{2}$, Lina Anadani ${ }^{3}$ \\ Department of Chemistry, Faculty of Science, University of Aleppo, Syria. \\ *11E-mail:dramadan@scs-net.org ordramadan1946@gmail.com; \\ ${ }^{2}$ E-mail:promandil955@gmail.com \\ ${ }^{3}$ E-mail:Linaaaa10@hotmail.com
}

\begin{abstract}
The effect of ripening time of the laurel fruits (from the region of Kassab in Syria) between October to December on the chemical composition of essential oils in laurel oil extracted from the fresh fruits (green, brown and black) by hexane using gas chromatographic analysis was studied. The ratios of essential oils change with the time of growth and with the maturation of the fruits. It was found that, for the first time, the light oils (as Hexanal and 3-Hexen-1-ol) are very large, especially in green fruits. This is due to the fact that, the oil was extracted with hexane from fresh fruits, while their proportions are almost non-existent if the oil is extracted using the old methods (used locally by boiling the fruits). Keeping the extracted oil (or even fruits) at room temperature for a long period (like it is followed industrially) leads to a sharp decrease in the percentage of essential oils in general and light essential oils in particular, or until the light oils disappear completely, this greatly affects the quality of healthy laurel soap, for which its uses laurel oil in Syria. Analysis by GC and GC-MS of the essential oils has allowed to identify 26 compounds representing $99.4 \%$ of the total content were directly identified after extracting laurel oil. There are eleven essential oils, which constitute more than $88 \%$, and they are: Hexanal, 3-Hexen-1-ol, alpha-Pinene, Sabinene, beta-Myrcene, alpha-Terpinine, orto-Cymene, 1,8-Cineol, Bornyl acetate, alpha-Terpinyl acetate and Eugenol methyl ether $(24.263 \%, 14.250 \%, 7.562 \%, 2.827 \%, 7.120 \%, 1.596 \%, 11.211 \%, 9.574 \%, 3.628 \%, 5.394 \%$ and $1.547 \%$ in green fruits at October; and 8.667\%, 3.098\%, 8.385\%, 8.956\%, 6.222\%, 1.538\%, 6.216\%, $41.311 \%, 3.089 \%, 3.378 \%$ and $1.002 \%$ in black fruits at December).
\end{abstract}

Keywords: Laurel oil, Essential oils, Gas chromatographic analysis. 


\section{Introduction}

The laurel plant is widely spread in the Syrian coast, especially in the Kassab [1].There are many studies on the chemical composition of the essential oil obtained from leaves of Mediterranean and European L. nobilis. The main components of the essential oil were cineole $(44.1 \%)$, eugenol $(15.2 \%)$, sabinene $(6.2 \%)$, 4terpineol (3.6\%), $\alpha$-pinene $(2.7 \%)$, methyl eugenol (2.5\%), $\alpha$-terpin-eol (2.2\%), and -pinene $(2.1 \%)[2]$

The oil yield was $0.78 \%, 0.80 \%$, and $3.25 \%$ in the fruits, twigs, and leaves, respectively. In the fruit 38 constituents representing $99.3 \%$ of the total content were identified. Twelve of the constituents were in concentrations over $1 \%$ of the essential oils. The main constituents in the fruit essential oils (above 3\%) were 1,8-cineole (33.3\%), $\alpha$-terpinyl acetate $(10.3 \%), \alpha$-pinene $(11.0 \%), \beta$-elemene $(7.45 \%)$, sabinene $(6.30 \%)$, $\beta$-phellandrene $(5.2 \%)$, bornyl acetate $(4.38 \%)$, and camphene (4.3\%) [3].

The laurel essential oils yield and composition were shown to be influenced by various factors, such as growth environment, harvest season, plant parts, extraction method, and others. The main compounds of the fruit essential oils in previous studies were 1,8-cineole $(8.10-48.0 \%), \alpha$ terpinylacetate $(3.67-10.4 \%)$, sabinene (4.49$11.4 \%), \alpha$-phellandrene, eugenol, methyl eugenol, $\alpha$-pinene, $\alpha$-ocimene, $\alpha$-pinene, etc., (3.91$12.8 \%$ ) [4-10].

In the present work, the effect of ripening time of the laurel fruits (from the region of Kassab in Syria) between October to December on the chemical composition of essential oils in laurel oil extracted from the fruits (green, brown and black) by hexane using gas chromatographic analysis was applied.

\section{Materials and Methods}

\section{Instruments and apparatuses}

A Shimadzu GC-2010 gas chromatograph with capillary column (TRB-1, $0.5 \mu \mathrm{m}, 30 \mathrm{~m} \times 0.25$ $\mathrm{mm}$, Serial: J-2031612), auto injecter-AOC-20i and FID detector were used. Agilent Technologies (GC-MS), 7890 A GC system, 5975C inert XL EI/Cl MSD with Triple-Axis Detector, made in USA, 2008. For microwave digestion of the samples, a high performance microwave digestion apparatus MLS-1200 MEGA with EM-30 unit (Milestone $\mathrm{GmbH}$ ) was used. An ultrasonic processor model POWER Sonic 405 was used. The diluter pipette model DIP-1 (Shimadzu), having $100 \mu \mathrm{L}$ sample syringe and five continuously adjustable pipettes covering a volume range from 10 to $5000 \mu \mathrm{L}$ (model Piptman P, GILSON). Centrifuge (Centurion Scientific Ltd., Model: K2080-Manufactured in the United Kingdom) was used for the preparation of the experimental solutions. SARTORIUS TE64 electronic balance was used for weighing the samples.

\section{Reagents}

Hexane and methanol (extra pure) were purchased from Merck. Two standards of essential oils CAN-TERP-MIX $1 \& 2$, which each contain 21 compounds by focus each $100 \mu \mathrm{g} . \mathrm{mL}^{-1}$ were used.

\section{Samples preparation}

Dry the fruits in room temperature in the shade for several days. Then extract the oil with hexane by distillation until the extraction is complete. The oil was extracted by hexane and collected in a glass container [1]. The essential oils were extracted by using a Clevenger apparatus (Figure 1) for three hours, and they were directly bound to the GC-2010 gas chromatograph after extending them with hexane in ratio $2 \mathrm{mg} \cdot \mathrm{mL}^{-1}$. The percentage of essential oils in laurel oil ranged between $4-6 \%$. 
Int. J. Curr. Res. Chem. Pharm. Sci. (2020). 7(4): 30-49

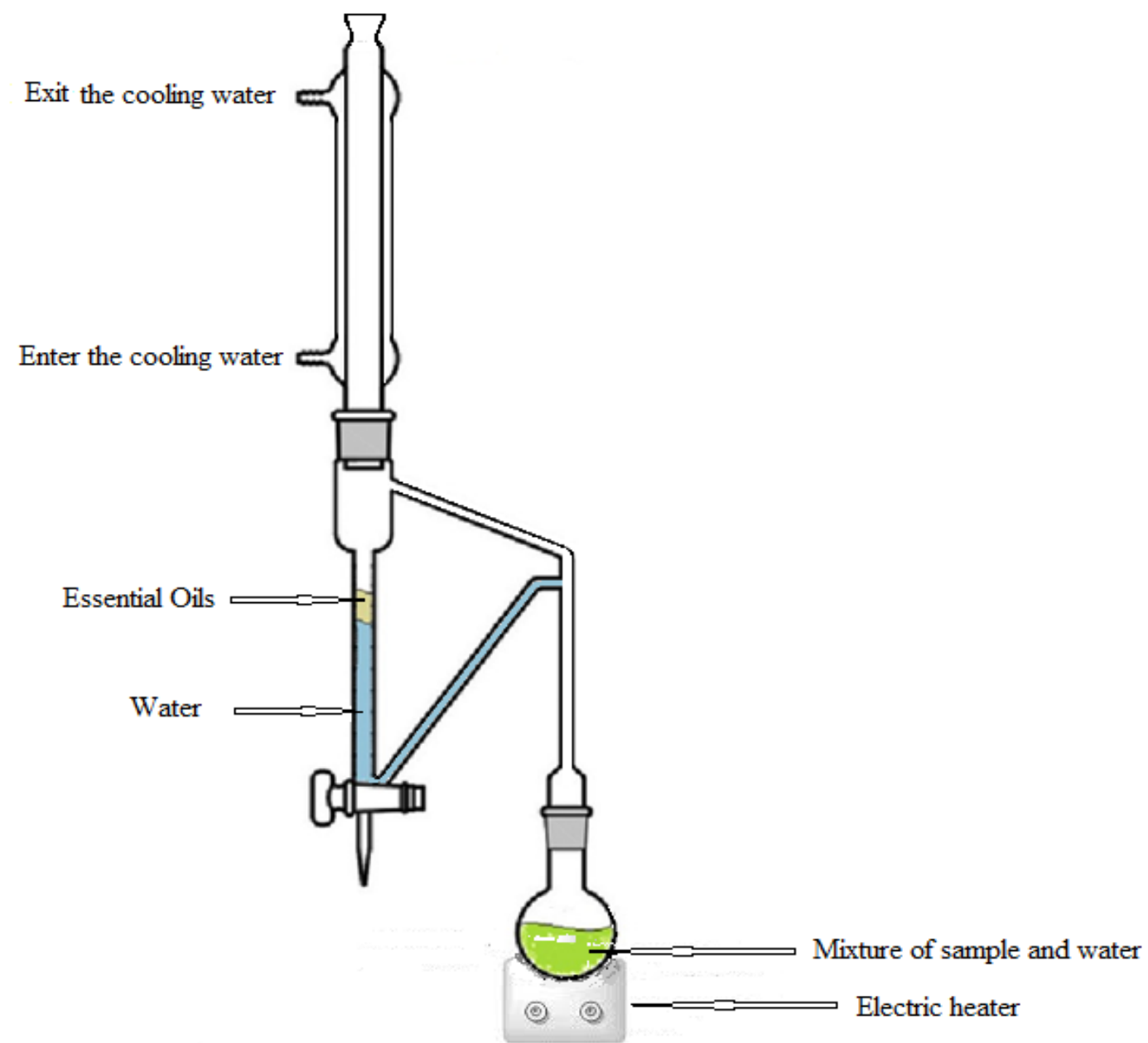

Figure 1. Clevenger apparatus

\section{Results and Discussion}

\section{Analytical procedure}

The effect of ripening time of the laurel fruits (from the region of Kassab in Syria) between October to December on the chemical composition of essential oils in laurel oil extracted from the fruits (green, brown and black) by hexane using gas chromatographic analysis was studied. Programmed column temperature $60^{\circ} \mathrm{C}$ for $5 \mathrm{~min}$ and then increase to $220^{\circ} \mathrm{C}$ with increasing temperature rate $2^{\circ} \mathrm{C} / \mathrm{min}$, flow rate of $\mathrm{N}_{2}$ carrier gas $2.1 \mathrm{~mL} \cdot \mathrm{min}^{-1}$, the injection volume $2 \mu \mathrm{L}$ with split injection mode 2.5 , injected port temperature $250^{\circ} \mathrm{C}$, and temperature of FID $250^{\circ} \mathrm{C}$.
Effect of ripening time in the chemical composition of essential oils in laurel oil

\section{On October 10.2019}

The components of essential oils using gas chromatography with a detector FID for oil extracted from the green, brown and black fruits on October 10.2019 were identified. An analysis by GC and GC-MS of the essential oils has allowed to identify 26 compounds representing $99.4 \%$ of the total content were determined, see Figures 2-4. There are eleven main essential oils, which constitute more than $88 \%$, and they are: Hexanal, 3-Hexen-1-ol, alpha-Pinene, Sabinene, beta-Myrcene, alpha-Terpinine, orto-Cymene, 1,8- Cineol, Bornyl acetate, alpha-Terpinyl acetate and Eugenol methyl ether (24.263\%, 
$14.250 \%, 7.562 \%, 2.827 \%, 7.120 \%, 1.596 \%$, $11.211 \%, 9.574 \%, 3.628 \%, 5.394 \%$ and $1.547 \%)$, respectively, for green fruits, $(18.758 \%, 10.424 \%$, $8.698 \%, 5.749 \%, 6.948 \%, 1.584 \%, 12.668 \%$, $14.260 \%, \quad 3.540 \%, \quad 4.825 \%$ and $1.330 \%)$, respectively, for brown fruits and $(16.049 \%$, $8.510 \%, 9.310 \%, 6.820 \%, 6.830 \%, 1.578 \%$, $13.730 \%, \quad 16.637 \%, 3.590 \%, \quad 4.438 \%$ and $1.102 \%)$, respectively, black fruits, see Tables 1-3 and Figure 5. The previous results show that the amounts of light volatile oils (such as Hexanal and 3-Hexen-1-ol) were very large and were decreasing with the transition from green to black fruits with average percentages of $77.3 \%$ and $73.1 \%$ of brown fruits, and $66.1 \%$ and $59.7 \%$ of black fruits, respectively, whereas some other oils (such as 1,8-Cineol, orto-Cymene and Sabinene) increased by an average of $1.49 \%, 1.12 \%$ and $2.03 \%$ for brown fruits, and $1.74 \%, 1.22 \%$ and $2.41 \%$ of the essential oils for black fruits mentioned in series.

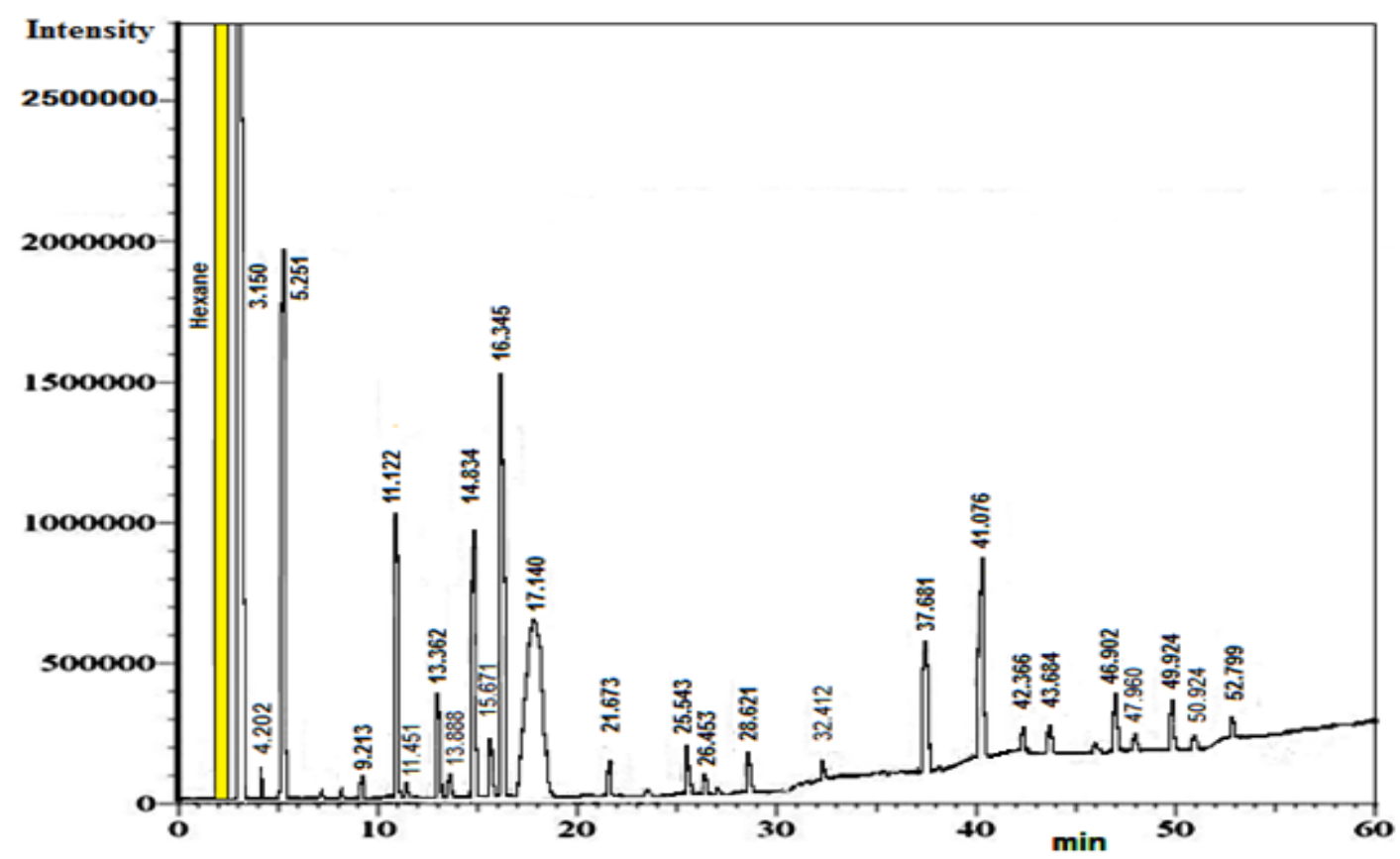

Fig. 2. Gas chromatographic analysis of essential oils in laurel oil extracted from green fruits on October 10.2019 (Programmed column temperature $60^{\circ} \mathrm{C}$ for $5 \mathrm{~min}$ and then increase it to $220^{\circ} \mathrm{C}$ with increasing temperature rate $2^{\circ} \mathrm{C} / \mathrm{min}$, flow rate of $\mathrm{N}_{2}$ carrier gas $2.1 \mathrm{~mL} \cdot \mathrm{min}^{-1}$, the injection volume $2 \mu \mathrm{L}$ with split injection mode 2.5 , injected port temperature $250^{\circ} \mathrm{C}$, and temperature of FID $250^{\circ} \mathrm{C}$ ). 
Int. J. Curr. Res. Chem. Pharm. Sci. (2020). 7(4): 30-49

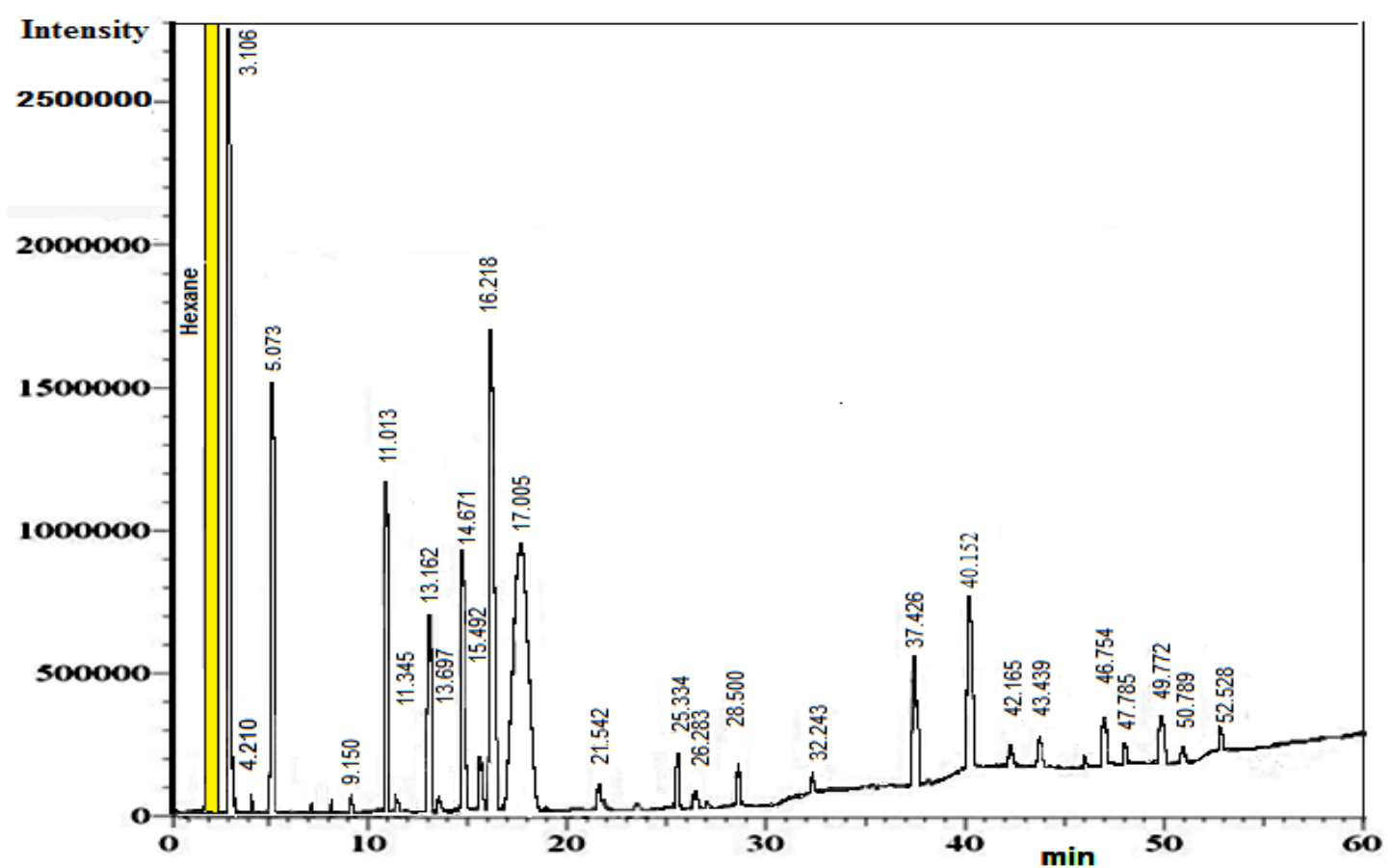

Fig.3. Gas chromatographic analysis of essential oils in laurel oil extracted from brown fruits on October 10.2019 (Programmed column temperature $60^{\circ} \mathrm{C}$ for $5 \mathrm{~min}$ and then increase it to $220^{\circ} \mathrm{C}$ with increasing temperature rate $2^{\circ} \mathrm{C} / \mathrm{min}$, flow rate of $\mathrm{N}_{2}$ carrier gas $2.1 \mathrm{~mL} \cdot \mathrm{min}^{-1}$, the injection volume $2 \mu \mathrm{L}$ with split injection mode 2.5 , injected port temperature $250^{\circ} \mathrm{C}$, and temperature of FID $250^{\circ} \mathrm{C}$ ).

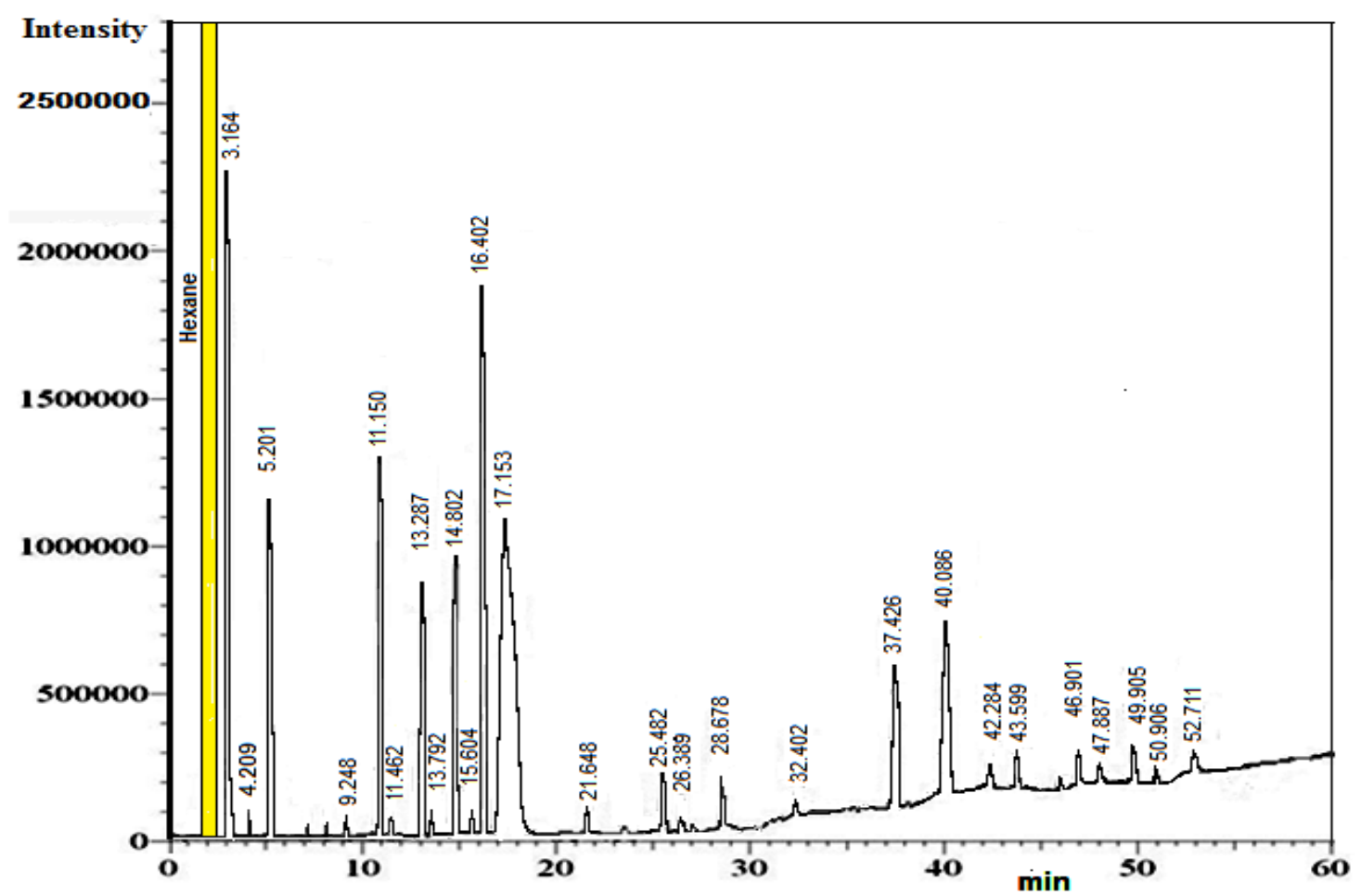

Fig. 4. Gas chromatographic analysis of essential oils in laurel oil extracted from black fruits on October 10.2019 (Programmed column temperature $60^{\circ} \mathrm{C}$ for $5 \mathrm{~min}$ and then increase it to $220^{\circ} \mathrm{C}$ with increasing temperature rate $2^{\circ} \mathrm{C} / \mathrm{min}$, flow rate of $\mathrm{N}_{2}$ carrier gas $2.1 \mathrm{~mL} \cdot \mathrm{min}^{-1}$, the injection volume $2 \mu \mathrm{L}$ with split injection mode 2.5 , injected port temperature $250^{\circ} \mathrm{C}$, and temperature of FID $250^{\circ} \mathrm{C}$ ). 
Int. J. Curr. Res. Chem. Pharm. Sci. (2020). 7(4): 30-49

Table 1. The components of essential oils extracted from the green fruits on October 10.2019 using gas chromatographic analysis with a detector FID.

\begin{tabular}{|c|c|c|c|}
\hline $\mathbf{N}^{\mathbf{0}}$ & Name of Essential Oil & $\begin{array}{c}\text { Retention time, } \\
\text { min }\end{array}$ & Concentration, \% \\
\hline 1 & Hexanal & 3.150 & 24.263 \\
\hline 2 & Unknown & 4.202 & 0.616 \\
\hline 3 & 3-Hexan-1-ol & 5.251 & 14.250 \\
\hline 4 & alpha-Thujene & 9.213 & 0.621 \\
\hline 5 & alpha-Pinene & 11.122 & 7.562 \\
\hline 6 & Camphene & 11.451 & 0.420 \\
\hline 7 & Sabinene & 13.362 & 2.827 \\
\hline 8 & beta-Pinene & 13.888 & 0.608 \\
\hline 9 & beta-Myrcene & 14.834 & 7.120 \\
\hline 10 & alpha-Terpinene & 15.671 & 1.596 \\
\hline 11 & o-Cymene & 16.345 & 11.211 \\
\hline 12 & 1.8-Cineol & 17.140 & 9.574 \\
\hline 13 & gamma-Terpinene & 21.673 & 0.904 \\
\hline 14 & Linalool & 25.543 & 1.356 \\
\hline 15 & p-Ment-2-en-1-ol & 26.453 & 0.381 \\
\hline 16 & Terpinen-4-ol & 28.621 & 1.118 \\
\hline 17 & alpha-Terpineol & 32.412 & 0.270 \\
\hline 18 & Bornyl acetate & 37.681 & 3.628 \\
\hline 19 & alpha-Terpinyl acetate & 41.076 & 5.394 \\
\hline 20 & Eugenol & 42.366 & 0.780 \\
\hline 21 & Cyctosativene & 43.684 & 0.912 \\
\hline 22 & Eugenol methyl ether & 46.902 & 1.547 \\
\hline 23 & beta-Elemene & 47.960 & 0.301 \\
\hline 24 & beta-Caryophyllene & 49.924 & 1.389 \\
\hline 25 & Cinnamyl acetate & 50.924 & 0.258 \\
\hline 26 & Isoeugenyl methyl ether & 52.799 & 0.514 \\
\hline \multicolumn{3}{|c|}{ Total } & 99.420 \\
\hline
\end{tabular}


Int. J. Curr. Res. Chem. Pharm. Sci. (2020). 7(4): 30-49

Table 2. The components of essential oils extracted from the brown fruits on October 10.2019 using gas chromatographic analysis with a detector FID.

\begin{tabular}{|c|lccc|}
\hline $\mathbf{N}^{\mathbf{0}}$ & Essential Oil & Retention time, min & Concentration, \% \\
\hline 1 & Hexanal & 3.106 & 18.758 \\
2 & Unknown & 4.210 & 0.489 \\
3 & 3-Hexan-1-ol & 5.073 & 10.424 \\
4 & alpha-Thujene & 9.150 & 0.618 \\
5 & alpha-Pinene & 11.013 & 8.698 \\
6 & Camphene & 11.345 & 0.452 \\
7 & Sabinene & 13.162 & 5.749 \\
8 & beta-Pinene & 13.697 & 0.615 \\
9 & beta-Myrcene & 14.671 & 6.948 \\
10 & alpha-Terpinene & 15.492 & 1.584 \\
11 & o-Cymene & 16.218 & 12.668 \\
12 & 1.8-Cineol & 17.005 & 14.260 \\
13 & gamma-Terpinene & 21.542 & 0.862 \\
14 & Linalool & 25.334 & 1.486 \\
15 & p-Ment-2-en-1-ol & 26.283 & 0.370 \\
16 & Terpinen-4-ol & 28.500 & 1.217 \\
17 & alpha-Terpineol & 32.243 & 0.281 \\
18 & Bornyl acetate & 37.426 & 3.540 \\
19 & alpha-Terpinyl acetate & 40.152 & 4.825 \\
20 & Eugenol & 42.165 & 0.731 \\
21 & Cyctosativene & 43.439 & 0.994 \\
22 & Eugenol methyl ether & 46.754 & 1.330 \\
23 & beta-Elemene & 47.785 & 0.413 \\
24 & beta-Caryophyllene & 49.772 & 1.304 \\
25 & Cinnamyl acetate & 50.789 & 0.273 \\
26 & Isoeugenyl methyl ether & 52.528 & 0.529 \\
\hline & & & $\mathbf{9 9 . 4 1 8}$ \\
& & & \\
\hline
\end{tabular}


Int. J. Curr. Res. Chem. Pharm. Sci. (2020). 7(4): 30-49

Table 3. The components of essential oils extracted from the black fruits on October 10.2019 using gas chromatographic analysis with a detector FID.

\begin{tabular}{|c|l|c|c|}
\hline $\mathbf{N}^{\mathbf{0}}$ & Essential Oil & Retention time, min & Concentration, \% \\
\hline 1 & Hexanal & 3.164 & 16.049 \\
2 & Unknown & 4.209 & 0.467 \\
3 & 3-Hexan-1-ol & 5.201 & 8.510 \\
4 & alpha-Thujene & 9.248 & 0.604 \\
5 & alpha-Pinene & 11.150 & 9.310 \\
6 & Camphene & 11.462 & 0.461 \\
7 & Sabinene & 13.287 & 6.820 \\
8 & beta-Pinene & 13.792 & 0.612 \\
9 & beta-Myrcene & 14.802 & 6.830 \\
10 & alpha-Terpinene & 15.604 & 1.578 \\
11 & o-Cymene & 16.402 & 13.730 \\
12 & 1.8-Cineol & 17.153 & 16.637 \\
13 & gamma-Terpinene & 21.648 & 0.846 \\
14 & Linalool & 25.482 & 1.520 \\
15 & p-Ment-2-en-1-ol & 26.389 & 0.362 \\
16 & Terpinen-4-ol & 28.678 & 1.340 \\
17 & alpha-Terpineol & 32.402 & 0.286 \\
18 & Bornyl acetate & 37.426 & 3.590 \\
19 & alpha-Terpinyl acetate & 40.086 & 4.438 \\
20 & Eugenol & 42.284 & 0.702 \\
21 & Cyctosativene & 43.599 & 1.120 \\
22 & Eugenol methyl ether & 46.901 & 1.102 \\
23 & beta-Elemene & 47.887 & 0.562 \\
24 & beta-Caryophyllene & 49.905 & 1.120 \\
25 & Cinnamyl acetate & 50.906 & 0.281 \\
26 & Isoeugenyl methyl ether & 52.711 & 0.532 \\
\hline & & & 99.409 \\
\hline
\end{tabular}


Int. J. Curr. Res. Chem. Pharm. Sci. (2020). 7(4): 30-49

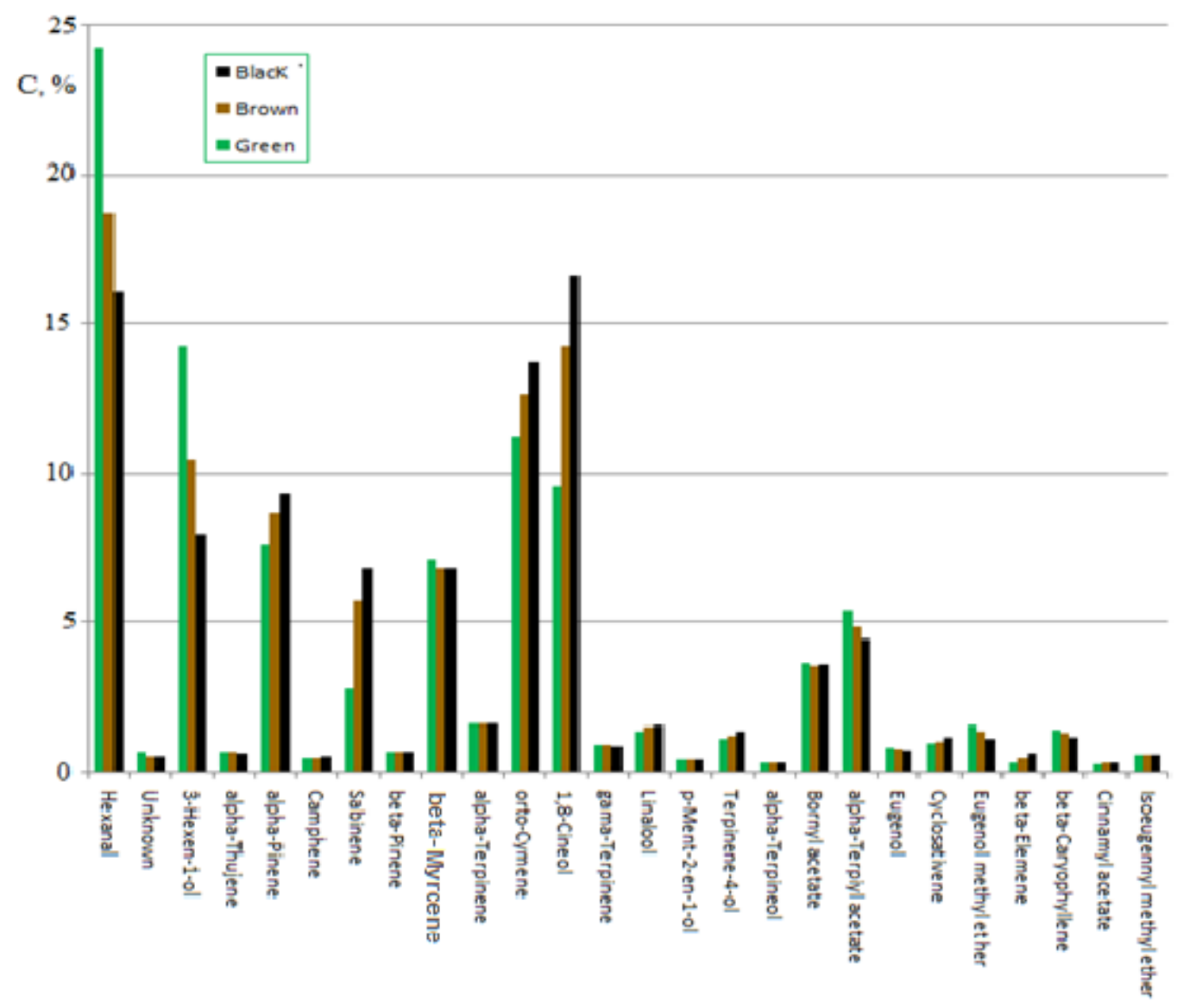

Fig. 5. The percentage of essential oils in laurel oil extracted from the fruits (green, brown and black) collected on October 10.2019.

\section{On November 10.2019}

A similar study on essential oils on November was conducted, see Figures 6-8. It was also found that there are eleven main essential oils, which constitute more than $88 \%$.Theyare: Hexanal, 3Hexen-1-ol, alpha-Pinene, Sabinene, betaMyrcene, alpha-Terpinine, orto-Cymene, 1,8Cineol, Bornyl acetate, alpha-Terpinyl acetate and Eugenol methyl ether $(20.212 \%, 12.360 \%$, $6.620 \%, 3.038 \%, 7.016 \%, 1.562 \%, 6.440 \%$, $23.813 \%, \quad 3.215 \%, \quad 4.960 \%$ and $1.310 \%)$, respectively, for green fruits, $(15.046 \%, 6.430 \%$, $7.989 \%, 5.080 \%, 6.818 \%, 1.558 \%, 9.437 \%$, $29.020 \%, 3.329 \%, 4.610 \%$ and $1.143 \%$ ), respectively, for brown fruits and (12.279\%,
$4.964 \%, 8.660 \%, 7.638 \%, 6.495 \%, 1.550 \%$, $9.640 \%, 30.696 \%, 3.460 \%, 3.829 \%$ and $1.030 \%$ ), respectively, black fruits, see Tables 4-6 and Figure 9. The previous results show that the amounts of light essential oils (such as Hexanal and 3-Hexen-1-ol) were large and were decreasing with the transition from green to black fruits with average percentages of $74.4 \%$ and $52.0 \%$ of brown fruits, and $60.7 \%$ and $40.1 \%$ of black fruits, respectively. Whereas, some other oils (such as 1,8-Cineol, orto-Cymene and Sabinene) increased by an average of $1.22 \%$, $1.46 \%$ and $1.67 \%$ for brown fruits, and $1.29 \%$, $1.50 \%$ and $2.51 \%$ of the essential oils for black fruits, respectively. 
Int. J. Curr. Res. Chem. Pharm. Sci. (2020). 7(4): 30-49

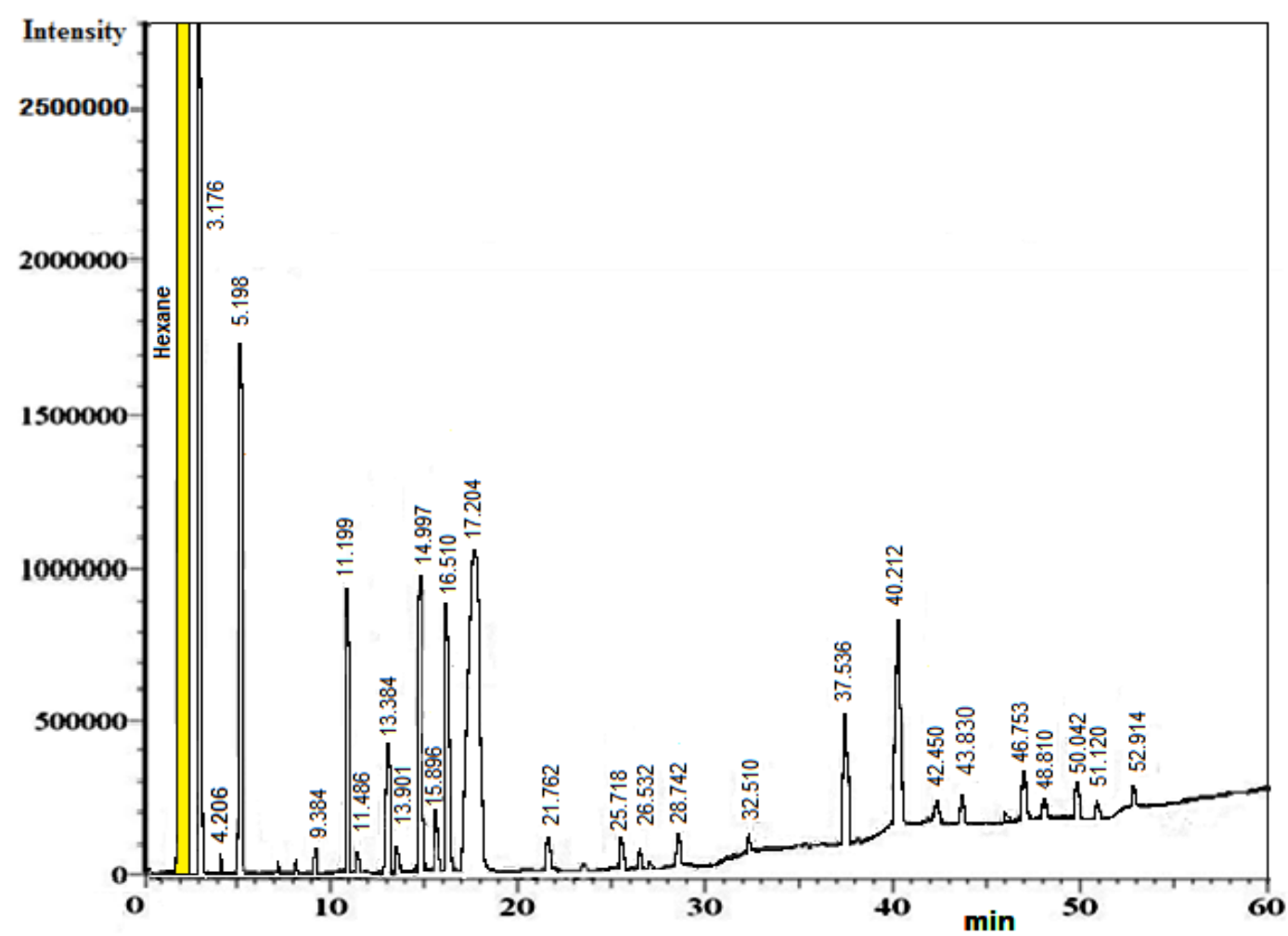

Fig. 6. Gas chromatographic analysis of essential oils in laurel oil extracted from green fruits on November 10.2019 (Programmed column temperature $60^{\circ} \mathrm{C}$ for $5 \mathrm{~min}$ and then increase it to $220^{\circ} \mathrm{C}$ with increasing temperature rate $2^{\circ} \mathrm{C} / \mathrm{min}$, flow rate of $\mathrm{N}_{2}$ carrier gas $2.1 \mathrm{~mL} \cdot \mathrm{min}^{-1}$, the injection volume $2 \mu \mathrm{L}$ with split injection mode 2.5 , injected port temperature $250^{\circ} \mathrm{C}$, and temperature of FID $250^{\circ} \mathrm{C}$ ).

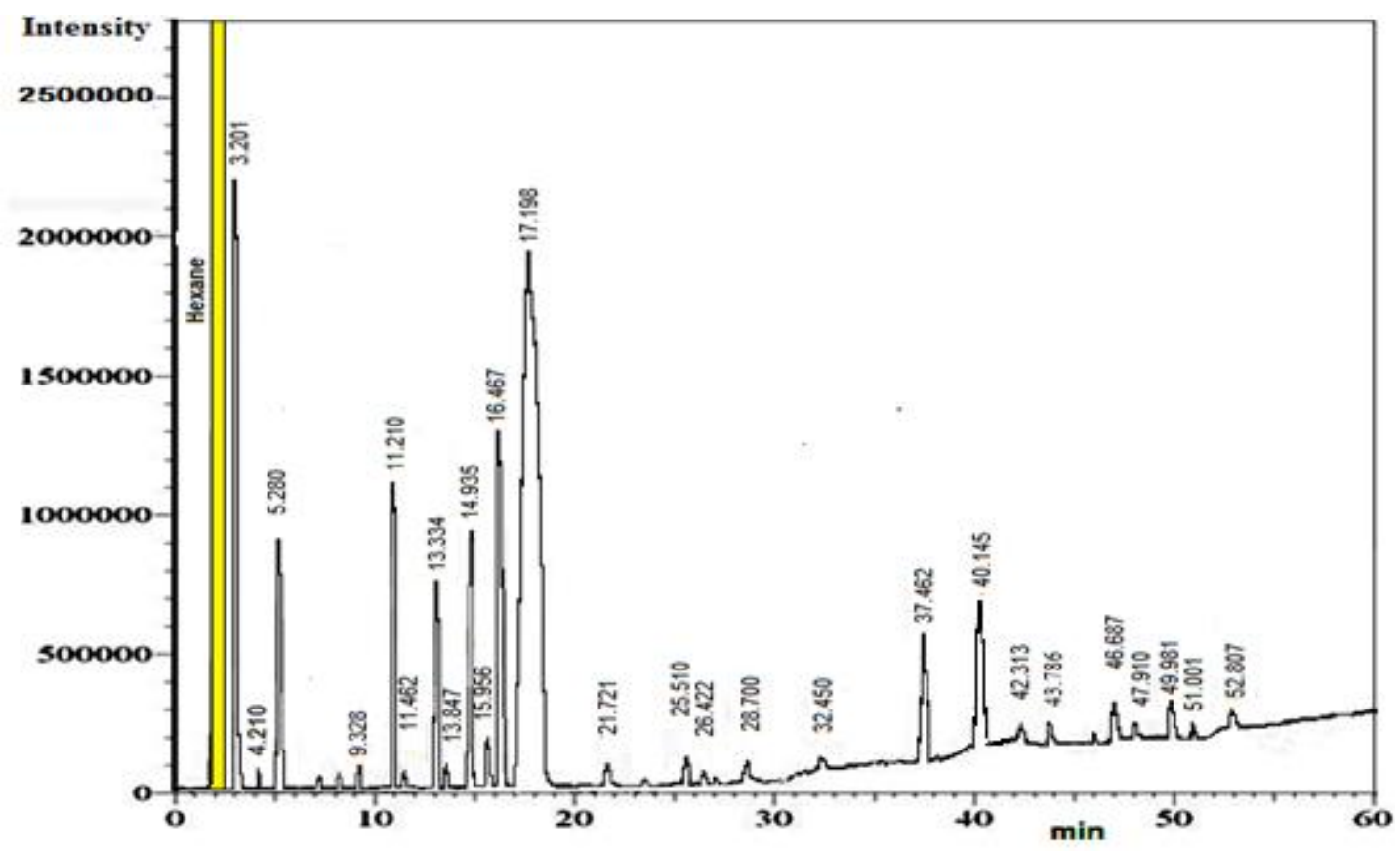

Fig.7. Gas chromatographic analysis of essential oils in laurel oil extracted from brown fruits on November 10.2019 (Programmed column temperature $60^{\circ} \mathrm{C}$ for $5 \mathrm{~min}$ and then increase it to $220^{\circ} \mathrm{C}$ with increasing temperature rate $2^{\circ} \mathrm{C} / \mathrm{min}$, flow rate of $\mathrm{N}_{2}$ carrier gas $2.1 \mathrm{~mL} \cdot \mathrm{min}^{-1}$, the injection volume $2 \mu \mathrm{L}$ with split injection mode 2.5 , injected port temperature $250^{\circ} \mathrm{C}$, and temperature of FID $250^{\circ} \mathrm{C}$ ). 


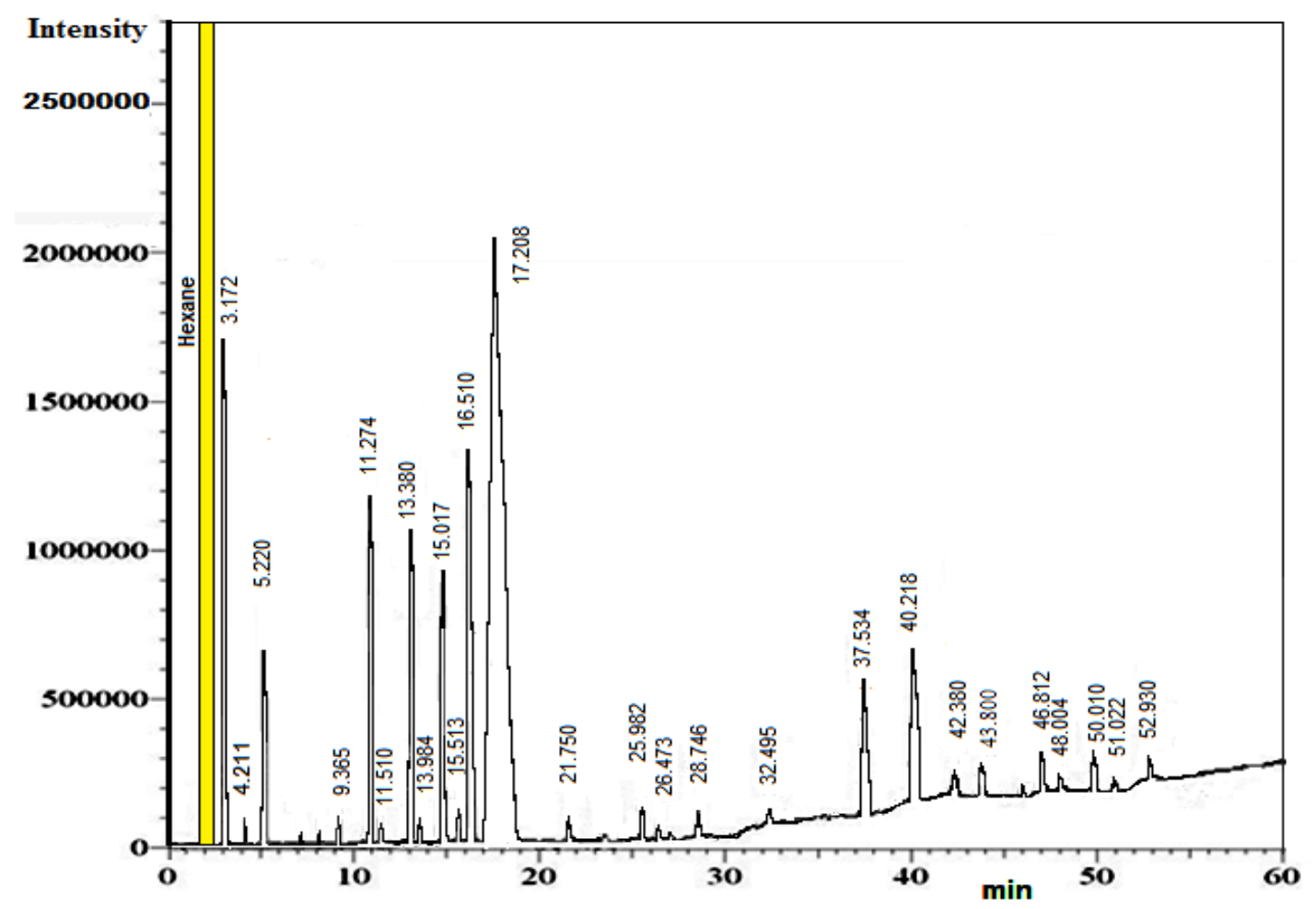

Fig. 8. Gas chromatographic analysis of essential oils in laurel oil extracted from black fruits on November 10.2019 (Programmed column temperature $60^{\circ} \mathrm{C}$ for $5 \mathrm{~min}$ and then increase it to $220^{\circ} \mathrm{C}$ with increasing temperature rate $2^{\circ} \mathrm{C} / \mathrm{min}$, flow rate of $\mathrm{N}_{2}$ carrier gas $2.1 \mathrm{~mL} \cdot \mathrm{min}^{-1}$, the injection volume $2 \mu \mathrm{L}$ with split injection mode 2.5 , injected port temperature $250^{\circ} \mathrm{C}$, and temperature of FID $250^{\circ} \mathrm{C}$ ).

Table 4. The components of essential oils extracted from the green fruits on November 10.2019 using gas chromatographic analysis with a detector FID.

\begin{tabular}{|c|lcc|}
\hline $\mathbf{N}^{\mathbf{0}}$ & Essential Oil & Retention time, $\mathbf{m i n}$ & Concentration, \% \\
\hline 1 & Hexanal & 3.176 & 20.212 \\
2 & Unknown & 4.206 & 0.502 \\
3 & 3-Hexan-1-ol & 5.198 & 12.360 \\
4 & alpha-Thujene & 9.384 & 0.602 \\
5 & alpha-Pinene & 1.1991 & 6.620 \\
6 & Camphene & 11.486 & 0.412 \\
7 & Sabinene & 13.384 & 3.038 \\
8 & beta-Pinene & 13.901 & 0.600 \\
9 & beta-Myrcene & 14.997 & 7.016 \\
10 & alpha-Terpinene & 15.896 & 1.562 \\
11 & o-Cymene & 16.510 & 6.440 \\
12 & 1.8-Cineol & 17.204 & 23.813 \\
13 & gamma-Terpinene & 21.762 & 0.884 \\
14 & Linalool & 25.718 & 0.903 \\
15 & p-Ment-2-en-1-ol & 26.532 & 0.374 \\
16 & Terpinen-4-ol & 28.742 & 0.830 \\
17 & alpha-Terpineol & 32.510 & 0.275 \\
18 & Bornyl acetate & 37.536 & 3.215 \\
19 & alpha-Terpinyl acetate & 40.212 & 4.960 \\
20 & Eugenol & 42.450 & \\
\hline
\end{tabular}


Int. J. Curr. Res. Chem. Pharm. Sci. (2020). 7(4): 30-49

\begin{tabular}{|l|llc|}
21 & Cyctosativene & 43.830 & 0.743 \\
22 & Eugenol methyl ether & 46.753 & 1.310 \\
23 & beta-Elemene & 48.810 & 0.264 \\
24 & beta-Caryophyllene & 50.042 & 1.100 \\
25 & Cinnamyl acetate & 51.120 & 0.243 \\
26 & Isoeugenyl methyl ether & 52.914 & 0.501 \\
\hline \multicolumn{2}{r}{ Total } & $\mathbf{9 9 . 4 0 7}$ \\
\hline
\end{tabular}

Table 5. The components of essential oils extracted from the brown fruits on November 10.2019 using gas chromatographic analysis with a detector FID.

\begin{tabular}{|c|l|c|c|}
\hline $\mathbf{N}^{\mathbf{0}}$ & Essential Oil & $\begin{array}{c}\text { Retention time, } \\
\text { min }\end{array}$ & Concentration, \% \\
\hline 1 & Hexanal & 3.201 & 15.046 \\
2 & Unknown & 4.210 & 0.401 \\
3 & 3-Hexan-1-ol & 5.280 & 6.430 \\
4 & alpha-Thujene & 9.328 & 0.584 \\
5 & alpha-Pinene & 11.210 & 7.989 \\
6 & Camphene & 11.462 & 0.415 \\
7 & Sabinene & 13.334 & 5.080 \\
8 & beta-Pinene & 3.8471 & 0.599 \\
9 & beta-Myrcene & 14.935 & 6.818 \\
10 & alpha-Terpinene & 15.956 & 1.558 \\
11 & o-Cymene & 16.467 & 9.437 \\
12 & 1.8-Cineol & 17.198 & 29.020 \\
13 & gamma-Terpinene & 21.721 & 0.852 \\
14 & Linalool & 25.510 & 1.068 \\
15 & p-Ment-2-en-1-ol & 26.422 & 0.361 \\
16 & Terpinen-4-ol & 28.700 & 0.850 \\
17 & alpha-Terpineol & 32.450 & 0.286 \\
18 & Bornyl acetate & 37.462 & 3.329 \\
19 & alpha-Terpinyl acetate & 40.145 & 4.610 \\
20 & Eugenol & 42.313 & 0.603 \\
21 & Cyctosativene & 43.786 & 0.792 \\
22 & Eugenol methyl ether & 46.687 & 1.143 \\
23 & beta-Elemene & 47.910 & 0.372 \\
24 & beta-Caryophyllene & 49.981 & 1.018 \\
25 & Cinnamyl acetate & 51.001 & 0.258 \\
26 & Isoeugenyl methyl & 52.807 & 0.516 \\
& ether & & $\mathbf{9 9 . 4 3 5}$ \\
\hline & & & \\
& & & \\
\hline
\end{tabular}


Int. J. Curr. Res. Chem. Pharm. Sci. (2020). 7(4): 30-49

Table 6. The components of essential oils extracted from the black fruits on November 10.2019 using gas chromatographic analysis with a detector FID.

\begin{tabular}{|c|l|c|c|}
\hline $\mathbf{N}^{\mathbf{0}}$ & Essential Oil & Retention time, min & Concentration, \% \\
\hline 1 & Hexanal & 3.172 & 12.279 \\
2 & Unknown & 4.211 & 0.392 \\
3 & 3-Hexan-1-ol & 5.220 & 4.964 \\
4 & alpha-Thujene & 9.365 & 0.579 \\
5 & alpha-Pinene & 11.274 & 8.660 \\
6 & Camphene & 11.510 & 0.418 \\
7 & Sabinene & 13.380 & 7.638 \\
8 & beta-Pinene & 13.984 & 0.598 \\
9 & beta-Myrcene & 15.017 & 6.495 \\
10 & alpha-Terpinene & 15.513 & 1.550 \\
11 & o-Cymene & 16.510 & 9.640 \\
12 & 1.8-Cineol & 17.208 & 30.696 \\
13 & gamma-Terpinene & 21.750 & 0.837 \\
14 & Linalool & 25.982 & 1.200 \\
15 & p-Ment-2-en-1-ol & 26.473 & 0.353 \\
16 & Terpinen-4-ol & 28.746 & 0.860 \\
17 & alpha-Terpineol & 32.495 & 0.291 \\
18 & Bornyl acetate & 37.534 & 3.460 \\
19 & alpha-Terpinyl acetate & 40.218 & 3.829 \\
20 & Eugenol & 42.380 & 0.598 \\
21 & Cyctosativene & 43.800 & 0.841 \\
22 & Eugenol methyl ether & 46.812 & 1.030 \\
23 & beta-Elemene & 48.004 & 0.418 \\
24 & beta-Caryophyllene & 50.010 & 0.990 \\
25 & Cinnamyl acetate & 51.022 & 0.262 \\
26 & Isoeugenyl methyl ether & 52.930 & 0.526 \\
\hline & & & 99.404 \\
& & &
\end{tabular}


Int. J. Curr. Res. Chem. Pharm. Sci. (2020). 7(4): 30-49

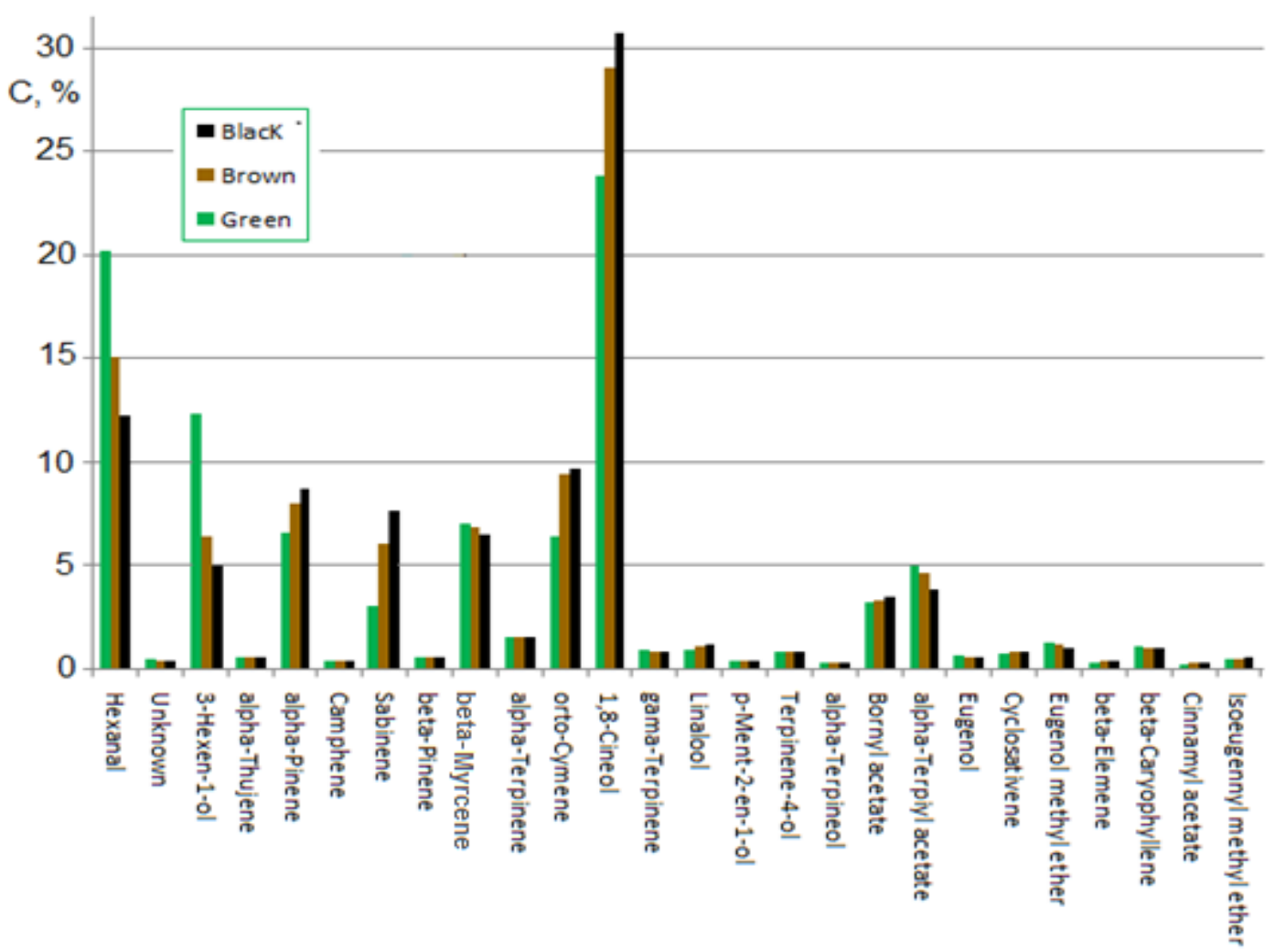

Fig. 9. The percentage of essential oils in laurel oil extracted from the fruits (green, brown and black) collected on November 10.2019.

\section{On December 10.2019}

A similar study on essential oils on December10.2019 was conducted, see Figures 1012. There are eleven main essential oils, which constitute more than $88 \%$, and they are: Hexanal, 3-Hexen-1-ol, alpha-Pinene, Sabinene, betaMyrcene, alpha-Terpinine, orto-Cymene, 1,8Cineol, Bornyl acetate, alpha-Terpinyl acetate and Eugenol methyl ether $(16.068 \%, 8.065 \%, 5.739 \%$, $3.168 \%, 6.994 \%, 1.554 \%, 3.368 \%$, 38.830\%, $3.077 \%, 4.119 \%$ and $1.143 \%$ ), respectively, for green fruits, $(11.702 \%, 4.246 \%, 7.818 \%, 6.820 \%$, $6.659 \%, 1.543 \%, 5.220 \%, 40.394 \%, 3.060 \%$, $3.565 \%$ and $1.014 \%$ ), respectively, for brown fruits and $(8.667 \%, 3.098 \%, 8.385 \%, 8.956 \%$, $6.222 \%, 1.538 \%, 6.216 \%, 41.311 \%, 3.089 \%$, $3.378 \%$ and $1.002 \%$ ), respectively, black fruits, see Tables7-9 and Figure13.The previous results show that the amounts of light essential oils (such as Hexanal and 3-Hexen-1-ol) were large and were decreasing with the transition from green to black fruits with average percentages of $72.8 \%$ and $52.6 \%$ of brown fruits, and $53.9 \%$ and $38.4 \%$ of black fruits, respectively. Whereas, some other oils (such as 1,8-Cineol, orto-Cymene and Sabinene) increased by an average of $1.04 \%$, $1.55 \%$ and $2.15 \%$ for brown fruits, and $1.06 \%$, $1.85 \%$ and $3.00 \%$ of the essential oils for black fruits, respectively.

The previous study shows that the ratios of essential oils change with the time of growth and with the maturation of the fruits. It was found that, for the first time, the light oils (as Hexanal and 3-Hexen-1-ol) are very large, especially in green fruits. This is due to the fact that we extract oil with hexane and from fresh fruits, while their proportions are almost non-existent if the oil is extracted using the old methods (used locally by boiling the fruits). Also, keeping the extracted oil (or even fruits) at room temperature for a long period (as it is followed industrially) leads to a sharp decrease in these light oils, or even their absence. 
Int. J. Curr. Res. Chem. Pharm. Sci. (2020). 7(4): 30-49

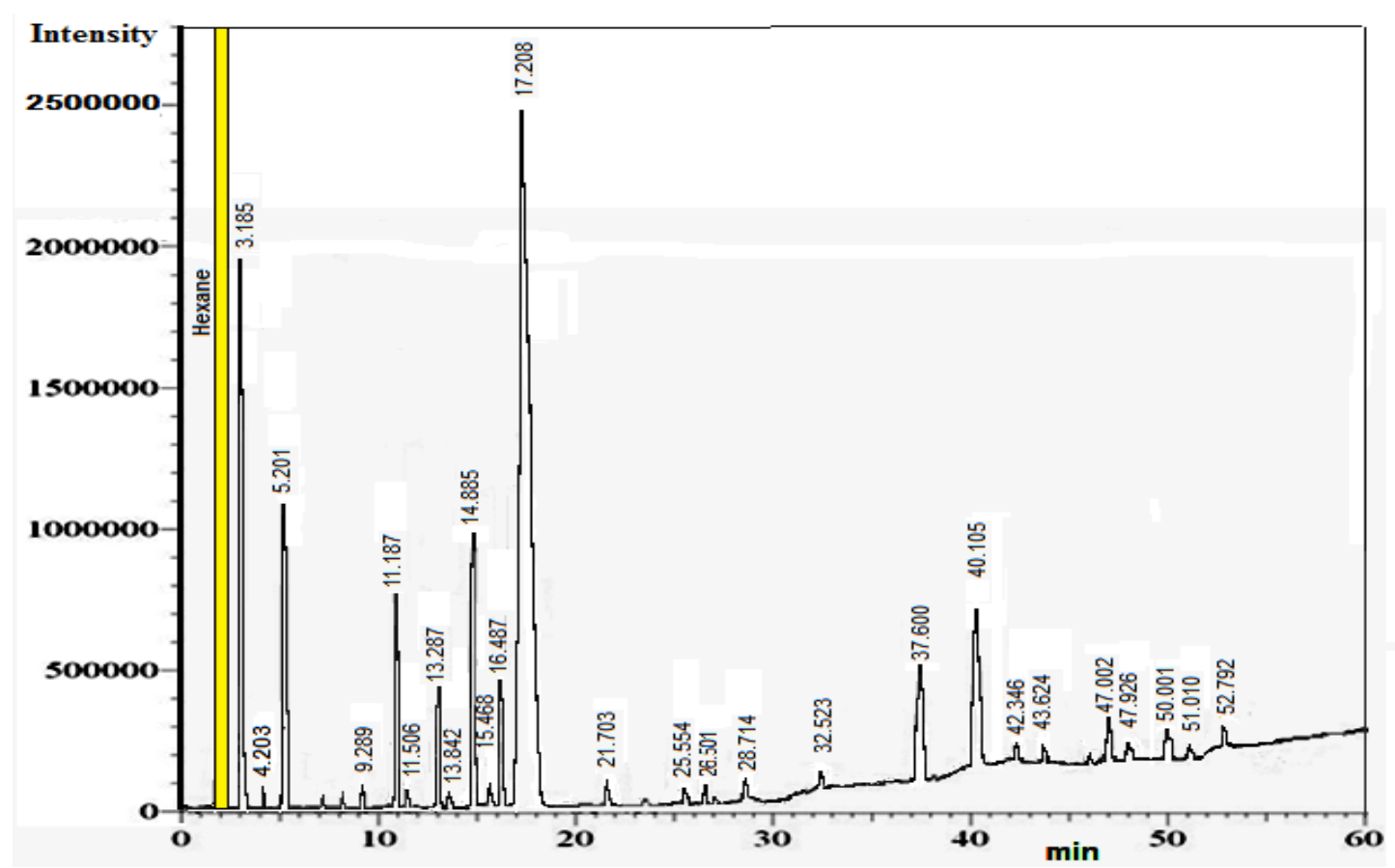

Fig.10. Gas chromatographic analysis of essential oils in laurel oil extracted from green fruits on December 10.2019 (Programmed column temperature $60^{\circ} \mathrm{C}$ for $5 \mathrm{~min}$ and then increase it to $220^{\circ} \mathrm{C}$ with increasing temperature rate $2^{\circ} \mathrm{C} / \mathrm{min}$, flow rate of $\mathrm{N}_{2}$ carrier gas $2.1 \mathrm{~mL} \cdot \mathrm{min}^{-1}$, the injection volume $2 \mu \mathrm{L}$ with split injection mode 2.5 , injected port temperature $250^{\circ} \mathrm{C}$, and temperature of FID $250^{\circ} \mathrm{C}$ ).

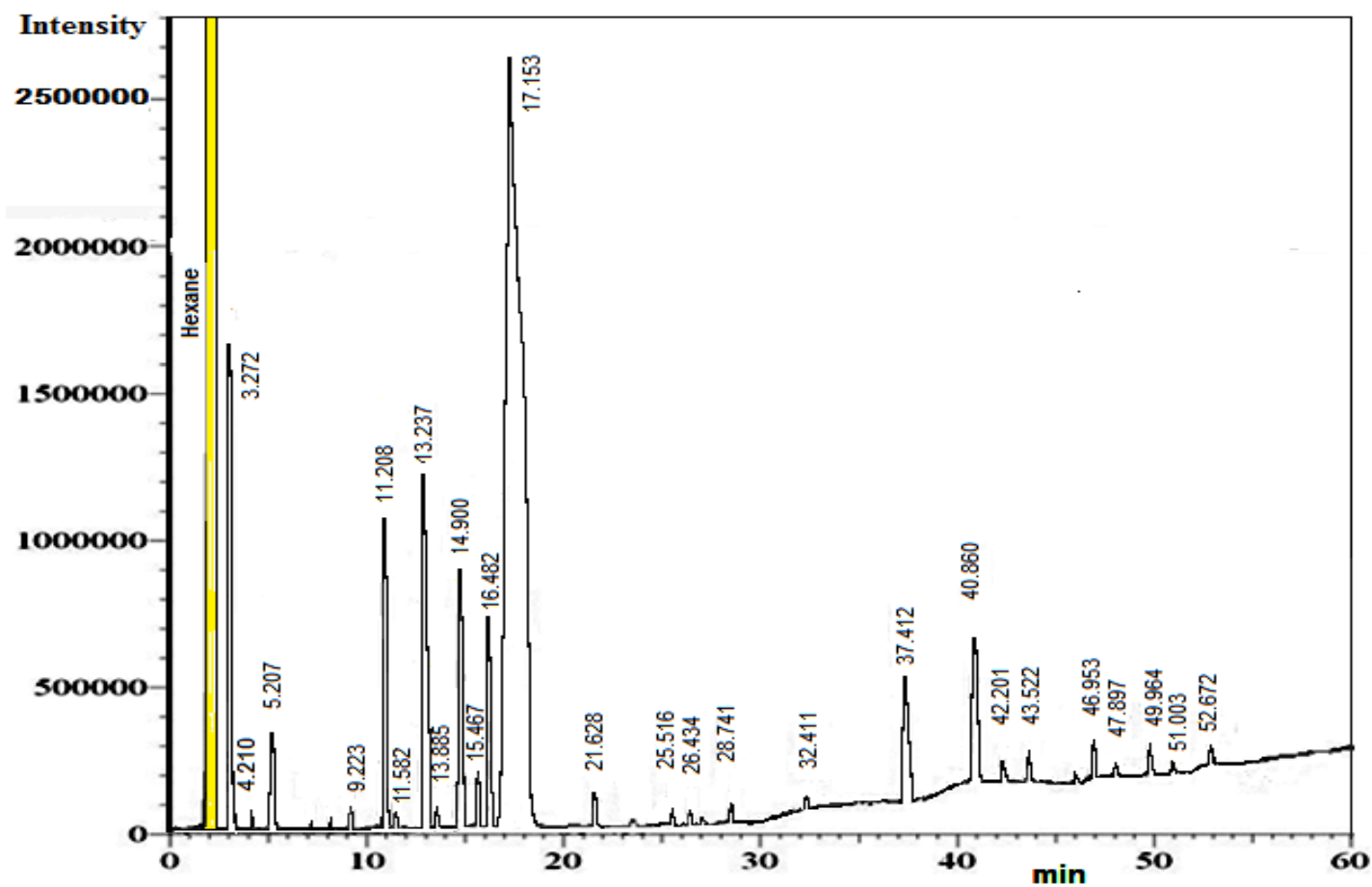

Fig.11. Gas chromatographic analysis of essential oils in laurel oil extracted from brown fruits on December 10.2019 (Programmed column temperature $60^{\circ} \mathrm{C}$ for $5 \mathrm{~min}$ and then increase it to $220^{\circ} \mathrm{C}$ with increasing temperature rate $2^{\circ} \mathrm{C} / \mathrm{min}$, flow rate of $\mathrm{N}_{2}$ carrier gas $2.1 \mathrm{~mL} \cdot \mathrm{min}^{-1}$, the injection volume $2 \mu \mathrm{L}$ with split injection mode 2.5 , injected port temperature $250^{\circ} \mathrm{C}$, and temperature of FID $250^{\circ} \mathrm{C}$ ). 
Int. J. Curr. Res. Chem. Pharm. Sci. (2020). 7(4): 30-49

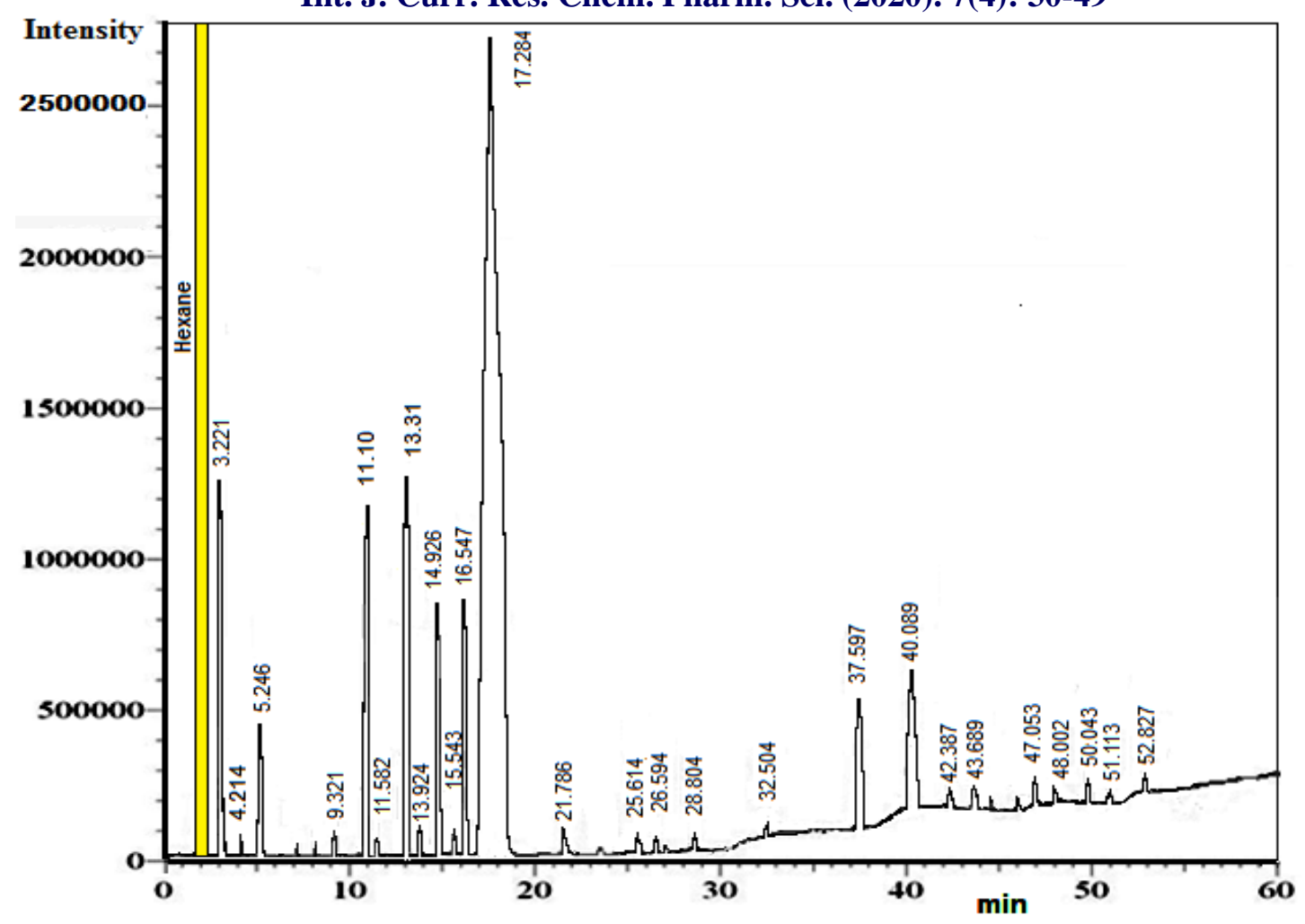

Fig.12. Gas chromatographic analysis of essential oils in laurel oil extracted from black fruits on December 10.2019 (Programmed column temperature $60^{\circ} \mathrm{C}$ for $5 \mathrm{~min}$ and then increase it to $220^{\circ} \mathrm{C}$ with increasing temperature rate $2^{\circ} \mathrm{C} / \mathrm{min}$, flow rate of $\mathrm{N}_{2}$ carrier gas $2.1 \mathrm{~mL} \cdot \mathrm{min}^{-1}$, the injection volume $2 \mu \mathrm{L}$ with split injection mode 2.5 , injected port temperature $250^{\circ} \mathrm{C}$, and temperature of FID $250^{\circ} \mathrm{C}$ ).

Table 7. The components of essential oils extracted from the green fruits on December 10.2019 using gas chromatographic analysis with a detector FID.

\begin{tabular}{|c|l|c|c|}
\hline $\mathbf{N}^{\mathbf{0}}$ & Essential Oil & Retention time, min & Concentration, \% \\
\hline 1 & Hexanal & 3.185 & 16.068 \\
2 & Unknown & 4.203 & 0.462 \\
3 & 3-Hexan-1-ol & 5.201 & 8.065 \\
4 & alpha-Thujene & 9.289 & 0.590 \\
5 & alpha-Pinene & 11.187 & 5.739 \\
6 & Camphene & 11.506 & 0.401 \\
7 & Sabinene & 13.287 & 3.168 \\
8 & beta-Pinene & 13.842 & 0.591 \\
9 & beta-Myrcene & 14.885 & 6.994 \\
10 & alpha-Terpinene & 15.468 & 1.554 \\
11 & o-Cymene & 16.487 & 3.368 \\
12 & 1.8-Cineol & 17.208 & 38.830 \\
13 & gamma-Terpinene & 21.703 & 0.874 \\
14 & Linalool & 25.554 & 0.317 \\
15 & p-Ment-2-en-1-ol & 26.501 & 0.360 \\
16 & Terpinen-4-ol & 28.714 & 0.419 \\
17 & alpha-Terpineol & 32.523 & 0.279 \\
& & &
\end{tabular}


Int. J. Curr. Res. Chem. Pharm. Sci. (2020). 7(4): 30-49

\begin{tabular}{|l|lll|} 
& & \\
18 & Bornyl acetate & 37.600 & 3.077 \\
19 & alpha-Terpinyl acetate & 40.105 & 4.119 \\
20 & Eugenol & 42.346 & 0.601 \\
21 & Cyctosativene & 43.624 & 0.620 \\
22 & Eugenol methyl ether & 47.002 & 1.143 \\
23 & beta-Elemene & 47.926 & 0.237 \\
24 & beta-Caryophyllene & 50.001 & 0.807 \\
25 & Cinnamyl acetate & 51.010 & 0.239 \\
26 & Isoeugenyl methyl & 52.792 & 0.492 \\
\hline & ether & & $\mathbf{9 9 . 4 1 4}$ \\
\hline
\end{tabular}

Table 8. The components of essential oils extracted from the brown fruits on December 10.2019 using gas chromatographic analysis with a detector FID.

\begin{tabular}{|c|c|c|c|}
\hline $\mathbf{N}^{\mathbf{0}}$ & Essential Oil & Retention time, min & Concentration, $\%$ \\
\hline 1 & Hexanal & 3.272 & 11.702 \\
\hline 2 & Unknown & 4.210 & 0.411 \\
\hline 3 & 3-Hexan-1-ol & 5.207 & 4.246 \\
\hline 4 & alpha-Thujene & 9.223 & 0.580 \\
\hline 5 & alpha-Pinene & 11.208 & 7.818 \\
\hline 6 & Camphene & 11.582 & 0.412 \\
\hline 7 & Sabinene & 13.237 & 6.820 \\
\hline 8 & beta-Pinene & 13.885 & 0.587 \\
\hline 9 & beta-Myrcene & 14.900 & 6.659 \\
\hline 10 & alpha-Terpinene & 15.467 & 1.543 \\
\hline 11 & o-Cymene & 16.482 & 5.220 \\
\hline 12 & 1.8-Cineol & 17.153 & 40.394 \\
\hline 13 & gamma-Terpinene & 21.628 & 0.843 \\
\hline 14 & Linalool & 25.516 & 0.398 \\
\hline 15 & p-Ment-2-en-1-ol & 26.434 & 0.352 \\
\hline 16 & Terpinen-4-ol & 28.741 & 0.447 \\
\hline 17 & alpha-Terpineol & 32.411 & 0.288 \\
\hline 18 & Bornyl acetate & 37.412 & 3.060 \\
\hline 19 & alpha-Terpinyl acetate & 40.860 & 3.565 \\
\hline 20 & Eugenol & 42.201 & 0.592 \\
\hline 21 & Cyctosativene & 43.522 & 0.712 \\
\hline 22 & Eugenol methyl ether & 46.953 & 1.014 \\
\hline 23 & beta-Elemene & 47.897 & 0.240 \\
\hline 24 & beta-Caryophyllene & 49.964 & 0.788 \\
\hline 25 & Cinnamyl acetate & 51.003 & 0.248 \\
\hline 26 & $\begin{array}{l}\text { Isoeugenyl methyl } \\
\text { ether }\end{array}$ & 52.672 & 0.513 \\
\hline \multicolumn{3}{|c|}{ Total } & 99.452 \\
\hline
\end{tabular}


Int. J. Curr. Res. Chem. Pharm. Sci. (2020). 7(4): 30-49

Table 9. The components of essential oils extracted from the black fruits on December 10.2019 using gas chromatographic analysis with a detector FID.

\begin{tabular}{|c|c|c|c|}
\hline $\mathbf{N}^{\mathbf{0}}$ & Essential Oil & Retention time, min & Concentration, \% \\
\hline 1 & Hexanal & 3.221 & 8.667 \\
\hline 2 & Unknown & 4.214 & 0.417 \\
\hline 3 & 3-Hexan-1-ol & 5.246 & 3.098 \\
\hline 4 & alpha-Thujene & 9.321 & 0.576 \\
\hline 5 & alpha-Pinene & 11.100 & 8.385 \\
\hline 6 & Camphene & 11.582 & 0.414 \\
\hline 7 & Sabinene & 13.310 & 8.956 \\
\hline 8 & beta-Pinene & 13.924 & 0.583 \\
\hline 9 & beta-Myrcene & 14.926 & 6.222 \\
\hline 10 & alpha-Terpinene & 15.543 & 1.538 \\
\hline 11 & o-Cymene & 16.547 & 6.216 \\
\hline 12 & 1.8-Cineol & 17.284 & 41.311 \\
\hline 13 & gamma-Terpinene & 21.786 & 0.829 \\
\hline 14 & Linalool & 25.614 & 0.450 \\
\hline 15 & p-Ment-2-en-1-ol & 26.594 & 0.346 \\
\hline 16 & Terpinen-4-ol & 28.804 & 0.490 \\
\hline 17 & alpha-Terpineol & 32.504 & 0.294 \\
\hline 18 & Bornyl acetate & 37.597 & 3.089 \\
\hline 19 & alpha-Terpinyl acetate & 40.089 & 3.378 \\
\hline 20 & Eugenol & 42.387 & 0.587 \\
\hline 21 & Cyctosativene & 43.689 & 0.826 \\
\hline 22 & Eugenol methyl ether & 47.053 & 1.002 \\
\hline 23 & beta-Elemene & 48.002 & 0.243 \\
\hline 24 & beta-Caryophyllene & 50.043 & 0.758 \\
\hline 25 & Cinnamyl acetate & 51.113 & 0.251 \\
\hline 26 & $\begin{array}{l}\text { Isoeugenyl methyl } \\
\text { ether }\end{array}$ & 52.827 & 0.513 \\
\hline \multicolumn{3}{|c|}{ Total } & 99.439 \\
\hline
\end{tabular}


Int. J. Curr. Res. Chem. Pharm. Sci. (2020). 7(4): 30-49

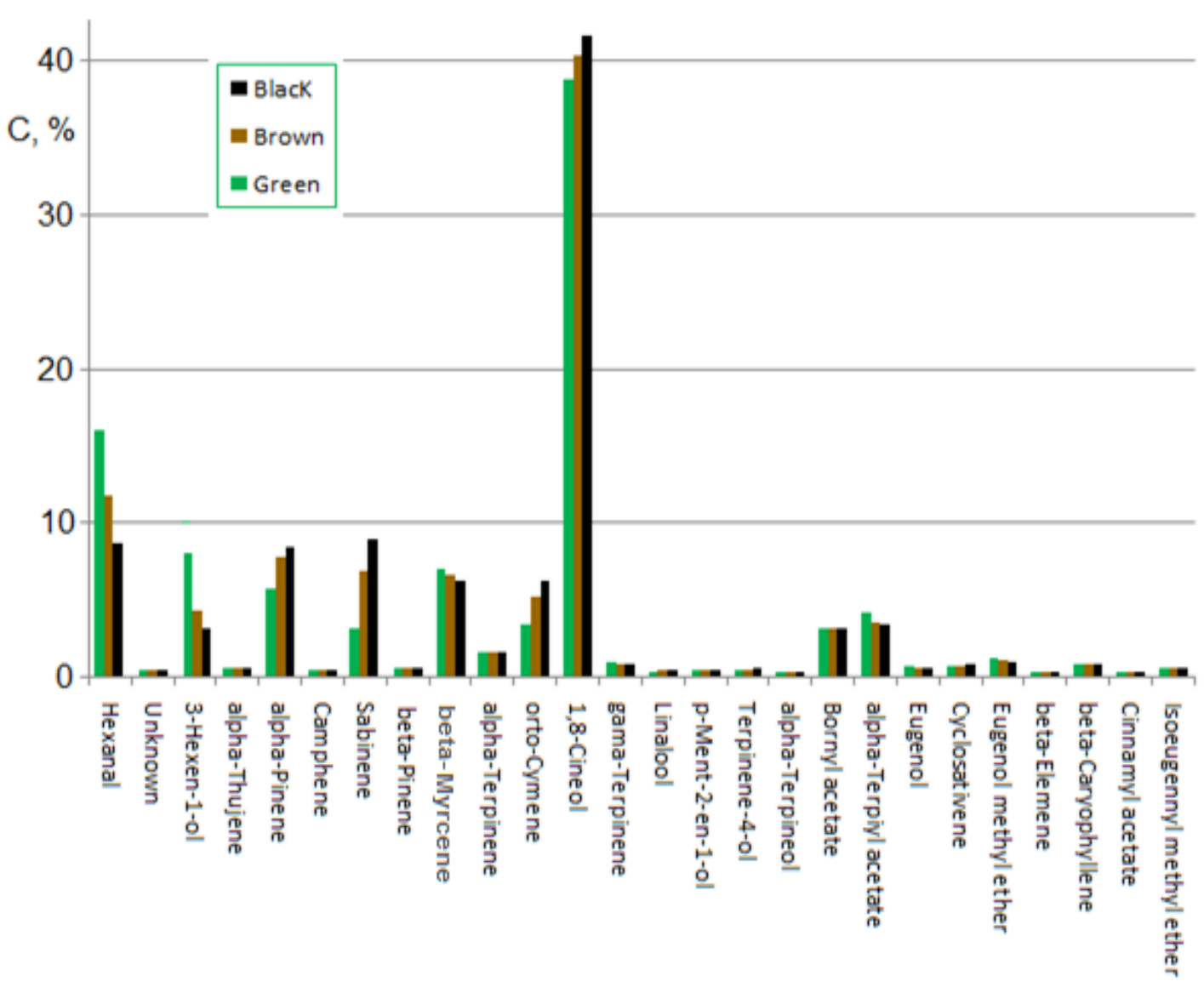

Fig. 13.The percentage of essential oils in laurel oil extracted from the fruits (green, brown and black) collected on December 10.2019

\section{Conclusion}

The effect of ripening time of the laurel fruits (from the region of Kassab in Syria) between October to December on the chemical composition of essential oils in laurel oil extracted from the fresh fruits (green, brown and black) by hexane using gas chromatographic analysis was studied. The ratios of essential oils change with the time of growth and with the maturation of the fruits. It was found that, for the first time, the light oils (as Hexanal and 3-Hexen-1-ol) are very large, especially in green fruits. This is due to the fact that, the oil was extracted with hexane from fresh fruits, while their proportions are almost nonexistent if the oil is extracted using the old methods (used locally by boiling the fruits). keeping the extracted oil (or even fruits) at room temperature for a long period (as it is followed industrially) leads to a sharp decrease in the percentage of essential oils in general and light oils in particular, or until the light oils disappear completely, this greatly affects the quality of healthy laurel soap, for which laurel oil is made in Syria. An analysis by GC and GC-MS of the essential oils has allowed to identify 26 compounds representing $99.4 \%$ of the total content were directly identified after extracting laurel oil. There are eleven essential oils, which constitute more than $88 \%$, and they are: Hexanal, 3-Hexen-1-ol, alpha-Pinene, Sabinene, betaMyrcene, alpha-Terpinine, orto-Cymene, 1,8Cineol, Bornyl acetate, alpha-Terpinyl acetate and Eugenol methyl ether. 


\section{References}

1 - Ramadan A.A., Mandil H.,Anadani L., 2019. "Effect of Ripening Time of Fruits in the Chemical Composition (\%) of Fatty Acids in Syrian Laurel Oil". Int. J. Curr. Res. Chem. Pharm. Sci. 6(7): 26-34.

2 - Zolfaghari B., Samsam-Shariat S.H., Ghannadi A., 2013. "Chemical Composition of Volatile Oils from the Endocarp and Hulls of Persian Bay Laurel Fruit: A Fragrant Herb Used In Traditional Iranian Medicine.”, JRPS, 2(31): $1-4$.

3 - Fidan H., Stefanova G., Kostova I., Stankov S., Damyanova S., 2019. "Chemical Composition and Antimicrobial Activity of Laurus nobilis L. Essential Oils from Bulgaria". Molecules, 24: 804-813.

4 - Kilic A., Hafizoglu H., Kollmannsberger H., Nitz S., 2004. "Volatile constituents and key odorants in leaves, buds, flowers, and fruit of Laurus nobilis L.”, J. Agric. Food Chem. 52: 1601-1606.

5 - Said C., Hüssein K., 2014. "Determination of the chemical and genetic differences of Laurus collected from three different geographic and climatic areas in Lebanon". Eur. Sci. J., 2: 412-419.
6 - Verdian-rizi M., Hadjiakhoondi A., 2008. "Essential oil composition of Laurus nobilis L. of different growth stages growing in Iran". Z. Naturforsch. C., 63: 785-788.

7 - Zekovic Z., Lepojevic Z., Mujic I., 2009. "Laurel extracts obtained by steam distillation, supercritical fluid and solvent extraction". J. Nat. Prod., 2: 104-109.

8 - Kivrak Ş., Göktürk T., Kivrak I., 2017. "Assessment of volatile oil composition, phenolics and antioxidant activity of Bay (Laurus nobilis) leaf and usage in cosmetic applications", Int. J. Sec. Metabolite, 4 (2): 148-161.

9 - Sangun M., Aydin E., Timur M., Karadeniz H., Caliskan M., Ozkan A., 2007. "Composition of chemical composition of the essential oil of Laurus nobilis L. leaves and fruit from different regions of Hatay". Turk. J. Environ. Biol, 28: 731-733.

10 - Marzouki H., Piras A., Marongiu B., Rosa A., Assunta M., 2008. "Extraction and separation of volatile and fixed oils from berries of Laurus nobilis L. by supercritical $\mathrm{CO}_{2}$ ". Molecules, 13: 1702-1711.

\begin{tabular}{|c|l|}
\hline \multicolumn{2}{|c|}{ Access this Article in Online } \\
\hline & Website: \\
\hline Q & www.ijcrcps.com \\
\hline Quick Response Code & \\
\hline DOI: $10.22192 /$ ijcrcps.2020.07.04.004 \\
\hline
\end{tabular}

How to cite this article:

Abdul Aziz Ramadan, Hasna Mandil, Lina Anadani. (2020). Effect of Ripening Time of Fruits in the Chemical Composition (\%) of Essential Oils in Syrian Laurel Oil. Int. J. Curr. Res. Chem. Pharm. Sci. 7(4): 30-49.

DOI: http://dx.doi.org/10.22192/ijcrcps.2020.07.04.004 